\title{
Cher Bruno...
}

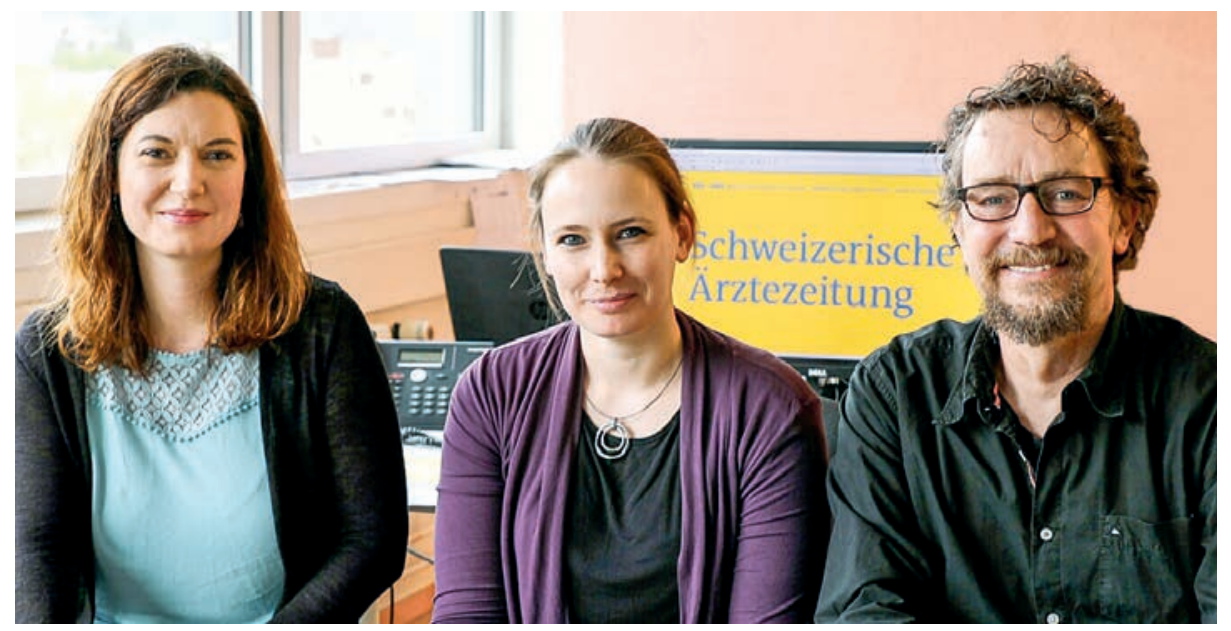

Die SÄZ ohne Dich - das geht eigentlich nich(t) ... Alle Deine Weggefährten haben fleissig in die Tasten gegriffen, um Dir mit diesem Schwerpunktheft einen schönen Abschied zu bereiten.

Elisa Jaun, Tanja Kühnle, Matthias Scholer (v.l.n.r.) Redaktionsteam SÄZ, Muttenz BL

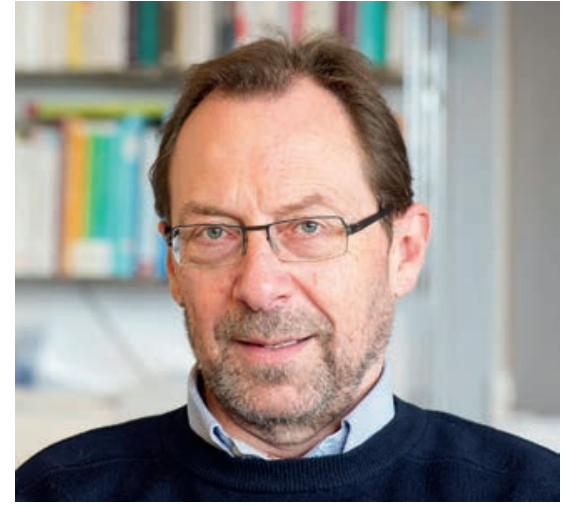

Heisse Themen? Ausgeglichen und unaufgeregt hast Du Lösungsansätze eingebracht. Für mich warst Du ein wichtiger Partner und Kollege, danke für Deine Unterstützung.

Hans Kurt Verwaltungsratspräsident EMH Schweizerischer Ärzteverlag

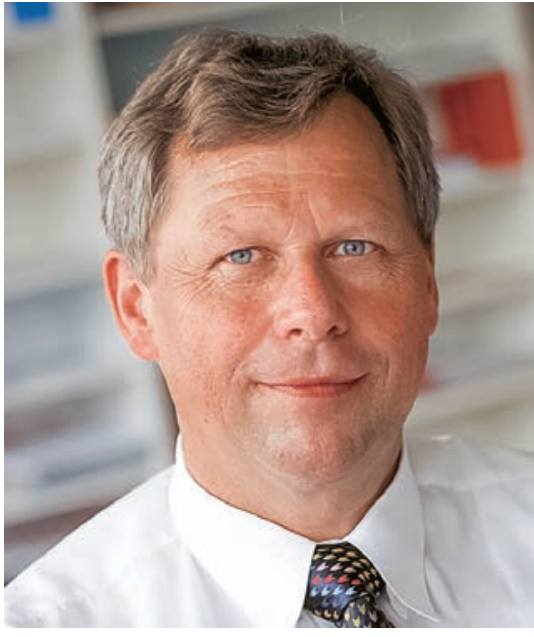

Du warst ein Glücksfall für alle - für die Leser, für die FMH, für EMH und somit für die Schweizerische Ärztezeitung und die Ärzteschaft.

Ruedi Bienz ehem. Inhaber und Geschäftsführer Schwabe AG und EMH Schweizerischer Ärzteverlag 


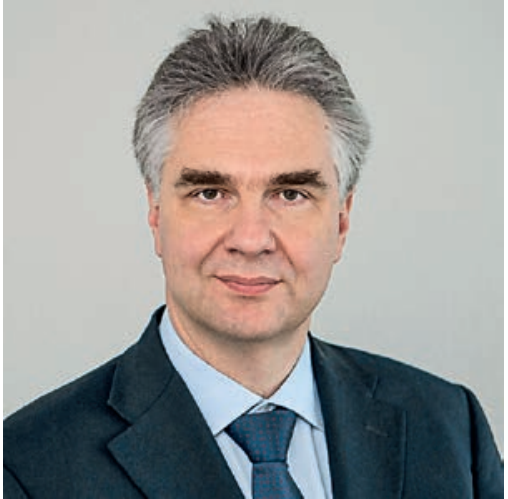

Du hast unter 40 Bewerbern als Einziger das Stelleninserat in der SÄZ und nicht anderswo gefunden und warst - nicht nur deshalb - der Richtige. Danke!

Ludwig Heuss Verwaltungsrat EMH Schweizerischer Ärzteverlag, Inhaber Petri Holding AG

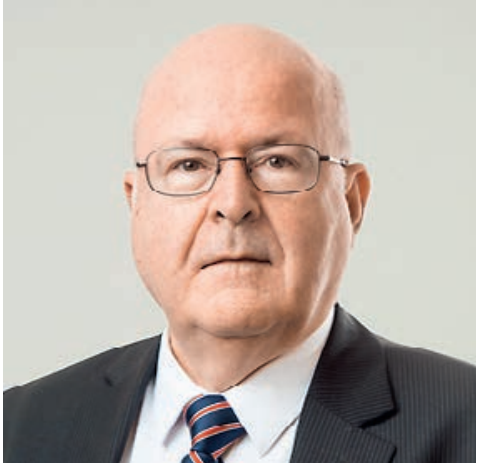

Mich hat die hohe Qualität Deiner journalistischen Arbeit immer beeindruckt. Ich wünschte mir, dass sich andere Medien daran ein Beispiel nehmen würden.

Werner Bauer Präsident des Schweizerischen Instituts für ärztliche Weiter- und Fortbildung SIWF

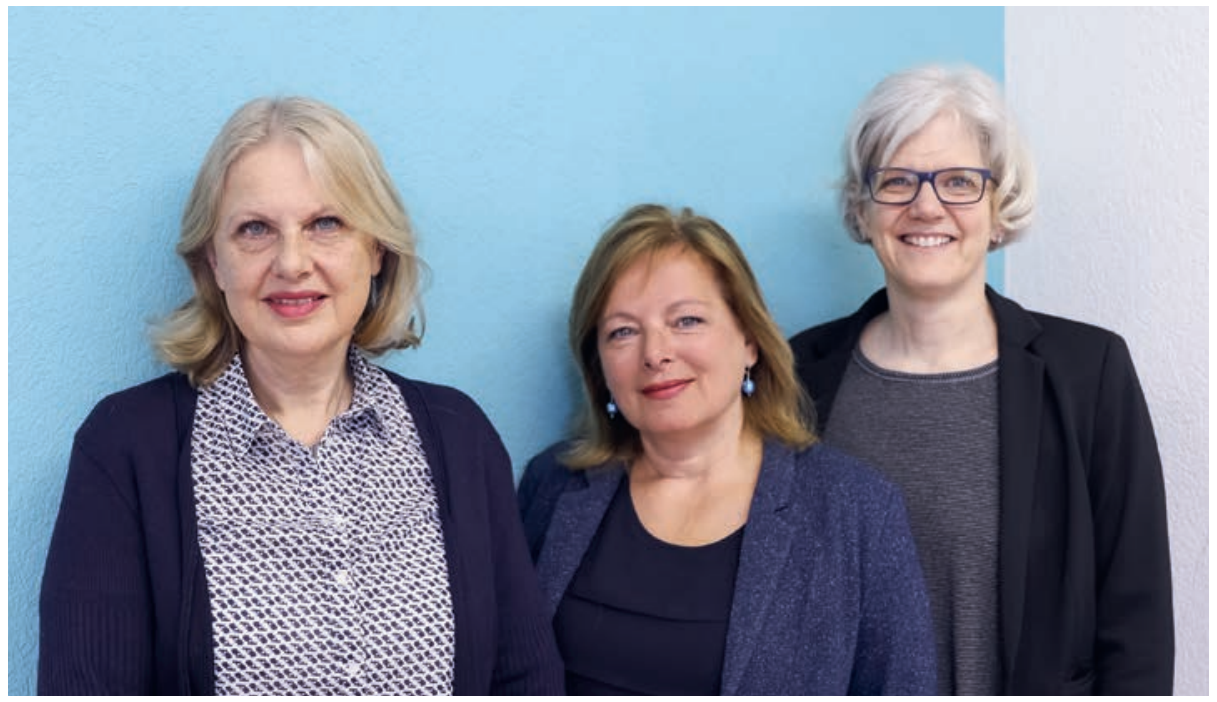

Wohlformulierte Texte, gute Diskussionen, Dein Gespür für Politics, E-Mails nachts um 12, das Bier nach der GL: Bruno, wir werden Dich vermissen!

Karin Würz, Natalie Marty, Sandra Ziegler (v.l.n.r.) Geschäftsleitung EMH Schweizerischer Ärzteverlag 


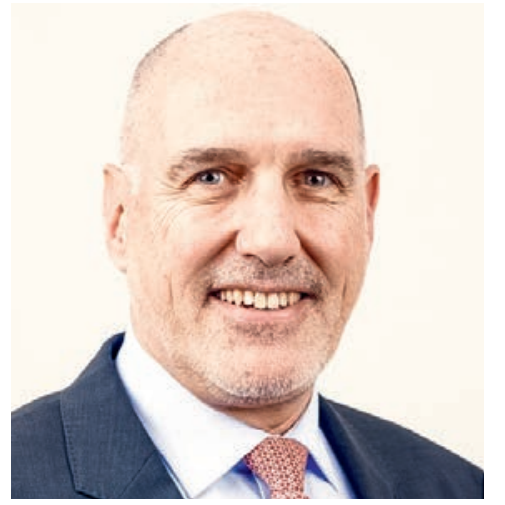

Wir werden Deine wunderbare Arbeit, Deine Offenheit, Deine Loyalität vermissen ... aber sicher nicht vergessen. Und glücklich sind Deine PatientInnen!

Jacques de Haller FMH-Präsident 2004-2012

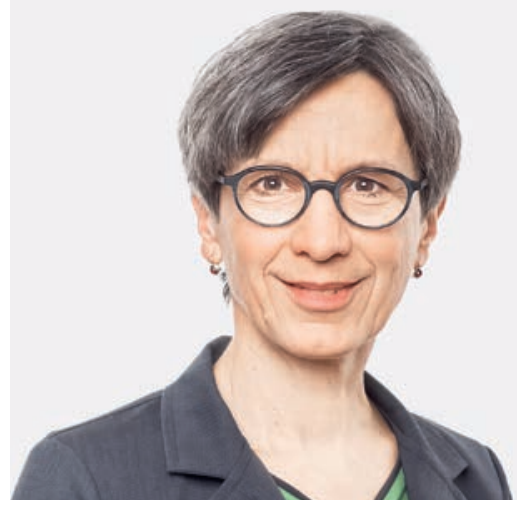

Medizin und Journalismus, beides kannst Du gut. Jetzt zieht es Dich wieder mehr zum Arztberuf, doch das Schreiben lässt Du zum Glück nicht bleiben!

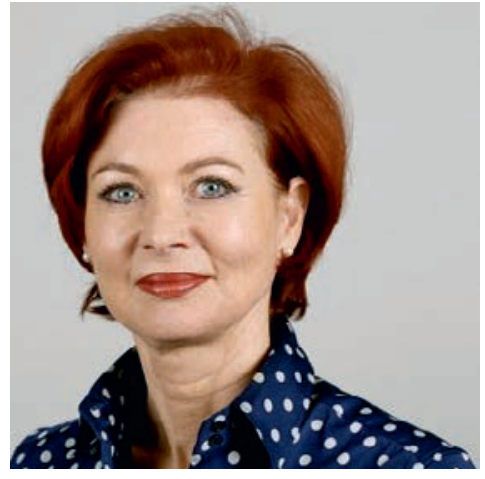

Totale Professionalität, Nerven wie Drahtseile - das habe ich immer an Dir bewundert. Danke für Dein Vertrauen, Deine Wertschätzung, die Super-SÄZ-Zeit.

Annette Eichholtz Managing Editorin SÄZ 2009-2016

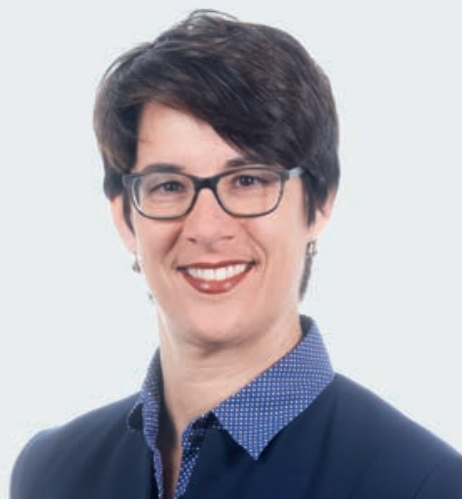

Zehn gemeinsame Berufsjahre ich bedanke mich für die tolle, spannende und vor allem auch humorvolle Zusammenarbeit zwischen Bern und Muttenz.

Jacqueline Wettstein Leiterin Kommunikation FMH 2007-2017

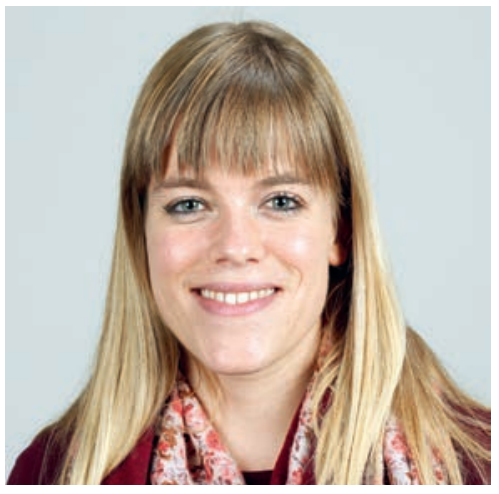

Von Dir habe ich gelernt, was das Verlagshandwerk ausmacht und was es heisst, im entscheidenden Moment mutig zu sein. Du warst ein wunderbarer Mentor. Danke!

Isabel Zwyssig Koordinierende Redaktorin SÄZ 2014-2017 


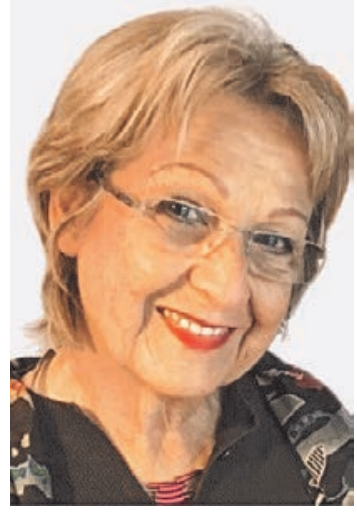

Unsere Zusammenarbeit hätte für mich nicht besser sein können. Du warst die Ruhe selbst, allzeit hilfsbereit, korrekt und voller Verständnis.

Vielen Dank für alles.

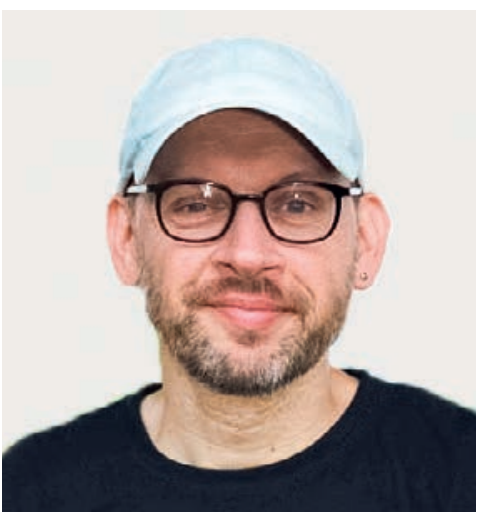

Leider haben wir es nie auf den Tennisplatz geschafft (Dein Linkshänderaufschlag hätte mich in den Wahnsinn getrieben), aber Du warst ein fairer (Mit-)Spieler.

Thomas Heuer Managing Editor SÄZ 1997-2009

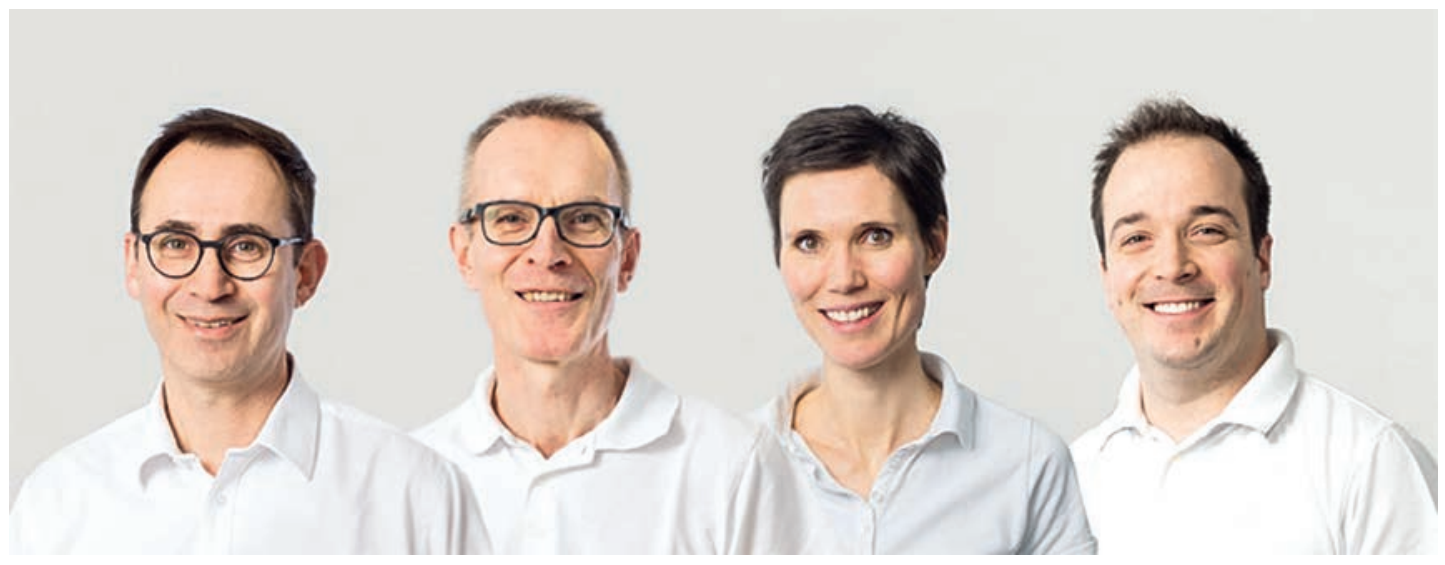

Wir freuen uns sehr auf die noch intensivere, sehr geschätzte Zusammenarbeit mit Dir, Bruno. Herzlich willkommen!

Lukas Steigmeier, Bruno Kesseli, Lena Hollinger-Mayer, Stefan Herger (v.l.n.r.) Arztpraxis AG Zentrum Oberdorf, Affoltern am Albis 